Direct applications of the diluted material to very small areas $(2 \mathrm{sq} . \mathrm{mm}$.) of the surface of the cerebral cortex cause localized convulsive alterations of the electrocorticogram.

Neuropsychiatric Institute,

Dargut Kemali University of Naples,

Policlinico, Naples.

${ }^{1}$ Wada, J., and Gibson, W. C., Amer. Med. Soc., Arch. Neurol. Psychiat., 81, 747 (1959).

${ }^{2}$ McGeer, E. G., Brown, W. T., and MeGeer, P. L.. J. Nerv. Ment. Diseases, 125.176 (1957).

' Decker, P., Z. ges: inn. Med. u. ihre Grenzgeb., 9, 966 (1954).

"Kemali, D., and Buscaino, V. M., "Chemical Concepts of Psychosis", ed. by Rinkel, M., 219 (McDowell-Obolensky, New York, 1958).

\section{Proximo-Distal Movement along the Axon of Protein synthesized in the Perikaryon of Regenerating Neurons}

DURING regeneration of crushed nerve-fibres of spinal ganglion cells, the turnover rate of proteins in the ganglia (C.7 and C.8) increases extensively, as compared with the controls ${ }^{1}$. This finding, on one hand, justifies the increase in protein in the perikaryon of the regenerating neuron ${ }^{1,2}$; on the other hand, it supports Weiss's opinion ${ }^{3}$ that some of the new proteins leave the body-cell and reach the growing end of the axon.

Movement of the protein along the axon can be studied by tagged compounds ${ }^{4,5}$, especially when a set experimental condition is followed; that is, in vivo only the perikaryon of regenerating nerve cells must synthesize labelled proteins from tagged precursors (for example, $C$ 14-amino-acids). Thus, if the 'new' proteins move along the axon, it should be possible to collect them at the regenerating end of the nerve fibre. It is clear that a labelled precursor of proteins in the blood would contaminate all boundaries of crushed neurons, giving rise to difficulties in the evaluation of the phenomenon.

Hypoglossal and vagus nerves of adult rabbits were exposed on one side and crushed by forceps cooled to $-70^{\circ} \mathrm{C}$.; the former at the level of the intermediate tendon of the digastric muscle; the latter at the carotid sinus. After 13 days, an opening was made on the middle nuchal line and a small window ( $\sim 3 \mathrm{~mm}$. diam.) was made through the atlo-occipital membrane. After removing the tela chorioidea of the fourth ventricle and drying the cerebrospinal fluid by filter paper, when necessary, the calamus scriptorius becomes clearly visible. About $0.001 \mathrm{ml}$. of Krebs and Henseleit solution ${ }^{6}$, containing $0 \cdot 2 \mathrm{gm}$. per cent of glucose, $5 \cdot 55 \mathrm{mgm}$. per cent of L-threonine${ }^{14} \mathrm{C}$ (S.A., $32.9 \mu \mathrm{c} . / \mathrm{mgm}$.) and $7.8 \mathrm{mgm}$. per cent of L-valine- ${ }^{14} \mathrm{C}$ (S.A., $68 \cdot 5 \mu \mathrm{c} . / \mathrm{mgm}$.), was placed on the calamus, using a micrometer syringe; the procedure was repeated every $20 \mathrm{~min}$. for $5 \mathrm{hr}$. In this way it was possible to concentrate the tagged amino-acids in the region of the hypoglossal nucleus and dorsal nucleus of the vagus, without introducing significant quantities of carbon-14 compounds into the blood or cerebrospinal fluid.

At different intervals after the experiment, the growing segments of the XII and X nerves, as well as the homologous segments of the other side, used as controls, were removed. Each tissue sample was homogenized in 9 vol. of 5 per cent cold trichloracetic acid and the suspension centrifuged; the procedure was repeated twice and the residue was washed successively three times with acetone and three times with ether. Finally, the dry residue was hydrolysed in $1 \mathrm{ml}$. of $6 \mathrm{~N}$ hydrochloric acid in a sealed tube at $115^{\circ} \mathrm{C}$. for $18 \mathrm{hr}$. The hydrolysate was brought to dryness at $50^{\circ} \mathrm{C}$. in air stream, taken up in water and transferred to a planchet for determination of radioactivity in a gas-flow counter.

The results can be summarized as follows: (1) During the first $30 \mathrm{hr}$. after commencement of the experiment, the regenerating segments of the XII and $\mathrm{X}$ nerves showed no radioactivity. (2) In the next $10 \mathrm{hr}$., the regenerating segments displayed a significant amount of radioactivity. This radioactivity was inseparable from threonine and valine, as was demonstrated by autoradiograms of the aminoacids from the protein hydrolysate separated by paper chromatography. The control segments did not show any radioactivity. (3) Between the fortieth and seventy-second hour, radioactivity was still present within the regenerating segments; no radioactivity was found in the homologous normal segments.

A detailed account of the experiments will be published elsewhere.

Department of Anatomy,

\section{N. MIANI}

University of Padua.

$$
\text { Nov. } 25 .
$$

${ }^{1}$ Miani, N., Rizzoli, A., and Bucciante, G., $J$. Neurochem. (in the press). 2 Brattgard, S.-O., Edström, J.-E., and Hydén, H., J. Neurochem., 1 , 316 (1957).

${ }^{3}$ Weiss, P., and Hiscoe, H. B., J. Exp. Zool., 107, 315 (1948).

"Gerard, R. W., in Weiss, P., "Genetic Neurolog." (Univ. of Chicago Press, Chicago, 1050).

5 Samuels, A. J., Boyarrsky, L. L., Gerard, R.JW., Libet, B., and Brust, M., Amer. 'J. Physiol., 164, 1 (1951).

${ }^{6}$ Krebs, H. A., and Henseleit, K., Hoppe-Seyl. Z. physiol. Chem., 210, $33(1932)$.

\section{Hæmostatic Mechanisms in the Animal Arterial Wall}

Depositron of fibrin on the interior surfaces of arteries after intimal injury forms the basis of the thrombogenic theory of the pathogenesis of arteriosclerosis ${ }^{1}$. Such fibrin deposits, covered by endothelium, have repeatedly been observed ${ }^{2-6}$.

Fibrin deposition in the organism is determined by a hæmostatic balance between fibrin formation and fibrin resolution, which is regulated by the mechanisms of blood coagulation and fibrinolysis,8. In order to try to substantiate the role of fibrin deposition as a primary process in the development of arteriosclerotic lesions, we studied the thromboplastic and fibrinolytic activities of the separated layers of the wall of the human aorta. We found high thrombo. plastic activity in the central layers (intima and media) and less activity in the adventitia. Little or no fibrinolytic activity was present in intima or media, while adventitia was highly fibrinolytic ${ }^{9}$. These results were verified by additional studies comprising samples of aortæ with varying degrees of atheromatosis ${ }^{10}$. The high thromboplastic activity of the human aorta (including intima) was recently confirmed ${ }^{11}$.

It has proved difficult, if not impossible, to produce experimentally in animals pathological changes identical with human arteriosclerotic lesions. This observed fact has never been satisfactorily explained.

However, an investigation of the fibrinolytic activity of samples of aortæ from monkeys demonstrated considerable activity in intima and media ${ }^{10}$. Furthermore, in bovine aorta low thromboplastic activity was found in the intima, while media and 